\title{
Strategic Marketing Management of Ski-Resorts in Bosnia and Herzegovina: A Competitive Analysis
}

\author{
Nedzma Begic \\ International Burch University, Faculty of Economics, Bosnia and Herzegovina \\ nedzma.begic@live.com \\ Teoman Duman \\ International Burch University, Faculty of Economics, Bosnia and Herzegovina \\ tduman@ibu.edu.ba
}

DOI: $\quad 10.6007 /$ IJARBSS/v3-i8/174 URL: http://dx.doi.org/10.6007/IJARBSS/v3-i8/174

\begin{abstract}
The purpose of this paper is to analyze competitive positions of five ski resorts in Bosnia and Herzegovina using Porter's generic competitive strategies. Bosnia and Herzegovina is rich with winter tourism opportunities and as a developing country it offers different customer groups more services in time. Managements of ski resorts in the country are looking for ways to strategically position their services to appeal more suitable customer bases. The results of qualitative analysis show that each ski resort in the country has its own strengths in regards to cost leadership, differentiation and focus strategies. Wiser strategies in marketing of these winter tourism services will help managements more productive business efforts.
\end{abstract}

Keywords: Ski Resorts, Bosnia and Herzegovina, Competition, Porter's Competitive Strategies

\section{Introduction}

Marketing strategy consists of selecting and analyzing the target markets (groups of people where the organization wants to sell) and the creation and maintenance of an appropriate marketing mix (product, price, distribution and promotion) that will meet needs and wants of these people. Marketing strategy includes a plan for the best and most efficient use of resources and tactics to achieve its goals. A good marketing strategy should be characterized as a clear market definition, a good blend of organizational strengths and needs of the market and superior performance compared to the competition in key factors of business success.

Marketing plays a very important role in strategic planning because it provides information and other inputs necessary for the preparation of a strategic plan. Conversely strategic planning defines the role of marketing in business organization. Guided by the strategic plan, marketing works closely with other parts of the business organization, with the aim of achieving and realizing strategic objectives. Marketing strategy implies planning and coordination of all marketing resources available to the integration of marketing mix elements, all in order to achieve the desired results with the previous targeted markets. All job offers are formed through marketing strategy in terms of product lines, communication, distribution and pricing. 
Competitive analysis is an important part of strategic marketing where companies continuously follow market and competitive trends to keep up with the current developments in business. This paper analyzes competitive strategies of ski-resorts in Bosnia and Herzegovina.

Bosnia and Herzegovina $(\mathrm{BH})$ is located in the central part of the Balkans and holds strategic seat in the eastern part of Europe. $\mathrm{BH}$ is a country in south-east Europe with an estimated population of four million people. $\mathrm{BH}$ is a country that measures just over $50,000 \mathrm{~km} 2$. Its diverse climate, contrast geographic landscape and multicultural and multi religious society may serve as magnet for tourist from around the Globe. The country is located in a beautiful mountainous location with many scenic vistas. Wilderness and untouched nature make it an ideal destination for adventurers and nature lovers. The central part of the country is covered with range of mountains and is a hikers and walkers paradise. Enchanted by both Mediterranean and Alpine climates, the range of diverse landscapes stun and amaze the county's visitors. Every mountain in $\mathrm{BH}$ can be utilized for winter tourism and they all are equally appealing and carry their peculiar charm. Mountains that are currently used for winter tourism are Bjelasnica \& Igman, Jahorina, Vlasic, Blidinje and Kupres (Enjoybosnia, 2010).

Bjelasnica and Jahorina mountains once hosted the 1984 Winter Olympics. They are a popular tourist attraction for skiing, boarding, paragliding, mountaineering and hiking. These mountains are only 20 minutes outside of Sarajevo. During the 1984 Winter Olympics, Bjelasnica was used for a number of Olympic events, and has several structures dating from that time, including hotels and skiing areas. Hotel Igman served as a seat to International Olympic Committee presided by late Juan Antonio Samaranch. Bosnian mountains used to attract world famous sports figures, athletes and sport managers but also many famous political figures. They were arenas for famous battles during World War II but also during recent war in Bosnia.

In the following sections of the paper a brief introduction to Porter's competitive strategies and winter tourism in $\mathrm{BH}$ will be presented. Competitive positions of different ski-resorts will be analyzed using Porter's competitive strategy model.

\section{Literature Review}

Competitive strategy is crucial to any firm in marketing since it has important effects on further development and position of a firm in the market. Also, it is a method that is used to differentiate a firm from its competitors.

The best explanation of competitive strategy has been given by Michael Porter. According to him, competitive strategy represents the search for the best suitable competitive position in an industry. He states that competitive strategy aims to establish a profitable and sustainable position against the forces that determine industry competition (Porter, 1985). Porter also emphasizes the important aspects of competitive strategy which are the structure of the industry and the position inside of the industry. Porter developed a special model concerning generic competitive strategies. He gives three main strategies: cost leadership, differentiation, and focus. The first strategy indicates that the firm is the low - cost producer of a product or provider of a service in an industry, along with charging industry average prices lower than those of rivals. Such firms have a cost advantage over others in certain segments of an industry. 
Cost advantage may include economies of scale, technology, preferential access to certain activities, materials, etc. In the second strategy, differentiation, the emphasis is on the uniqueness. The firm should use one specific attribute which will make it different from the others, whether it is a product, marketing approach, and so on. This strategy requires constant innovation and development of new products in order to take over the industry. The third strategy, focus, refers to one specific focus within the industry. It has two versions, cost focus and differentiation focus. Cost focus seeks for competitive advantage, while differentiation focus seeks for differentiation. Both of these strategies differentiate focuser's targets from those of others. However, this strategy is risky, and the great risk is that success can be shattered if a new technology or changing market needs make the firm's niche skills excessive. Even if the firm recovers from those changes in the short term, "the focus that they gave to the niche make it very difficult to switch to a new niche both in terms of competences available within the firm and credibility in the market" (Bachelor of International Management, n.d).

Just in any business, cost leadership, differentiation and focus strategies are important in services. In this paper, these three strategies are used to analyze competitive strategies of five ski resorts in $\mathrm{BH}$. In the eyes of service customers, these three aspects of products are as important as each other and the service providers have to compete based on providing best services in regards to these three strategies. As for, cost leadership, current economic downturn may be a reason why customers look for good value which can only be offered by companies reaching cost leadership position in their industries. Similarly, as for differentiation, today's knowledgeable customers are constantly looking for novel experiences which in fact are created by new firms in different industries. Also, companies today understand that having a unique expertise in a certain business area, help in developing product portfolio which will help companies to reach differentiation and cost leadership positions. The following section gives an overview of the winter tourism industry in $\mathrm{BH}$. Competitive positions of the ski-resorts will be analyzed following the literature review.

\section{Winter Tourism In in Bosnia and Herzegovina}

$\mathrm{BH}$ is endowed with beautiful mountains that are underutilized since there are only five winter resorts in the whole country. Those are: Bjelasnica and Igman, Jahorina, Vlasic, Blidinje and Kupres. Although, Bjelasnica and Igman, Jahorina and Vlasic stand out as better organized and with better offer yet there is a huge prospect and immense potential to offer great many new products in winter tourism (FIPA, 2010). Table 1 summarizes winter tourism facilities for the five ski resorts in $\mathrm{BH}$. 
Table 1: $\quad$ A comparison of winter tourism facilities of five ski-resorts in $\mathrm{BH}$.

\begin{tabular}{|c|c|c|c|c|c|}
\hline $\begin{array}{l}\text { Existing/Plann } \\
\text { ed Facilities }\end{array}$ & Igman \& Bjelasnica & Jahorina & Vlasic & Blidinje & Kupres \\
\hline $\begin{array}{l}\text { Accommodati } \\
\text { on }\end{array}$ & $\begin{array}{l}2250 \text { beds ( } 3 \text { hotels } \\
\text { with } 342 \text { beds, and } \\
\text { the rest are private) }\end{array}$ & $\begin{array}{l}4000 \text { beds ( } \\
6 \quad \text { hotels } \\
\text { with } 1022 \\
\text { beds, the } \\
\text { rest private) }\end{array}$ & $\begin{array}{l}6000 \text { beds } \\
\text { (6 hotels } \\
\text { with } 680 \\
\text { beds, and } \\
\text { the rest are } \\
\text { private) }\end{array}$ & $\begin{array}{l}2000 \text { beds } \\
\text { (1 hotel } \\
\text { and } \\
\text { private) }\end{array}$ & 700 beds \\
\hline $\begin{array}{l}\text { Ski lifts } \\
\text { capacity }\end{array}$ & $\begin{array}{l}5000 \text { person } / \mathrm{h} \\
22.200 \text { person } / \mathrm{h} \\
\text { planned }\end{array}$ & $\begin{array}{l}7500 \\
\text { person/h } \\
13.800 \\
\text { person/h } \\
\text { planned } \\
\end{array}$ & $\begin{array}{l}5400 \\
\text { person/h } \\
15.000 \\
\text { person/h } \\
\text { planned } \\
\end{array}$ & $\begin{array}{l}2500 \\
\text { person/h }\end{array}$ & $\begin{array}{l}1000 \\
\text { person/h }\end{array}$ \\
\hline $\begin{array}{l}\text { Alpine ski } \\
\text { slope }\end{array}$ & $12.200 \mathrm{~m}$ & $25.000 \mathrm{~m}$ & $14.000 \mathrm{~m}$ & $4.500 \mathrm{~m}$ & $14.000 \mathrm{~m}$ \\
\hline $\begin{array}{l}\text { Snowmaking } \\
\text { machines }\end{array}$ & $\begin{array}{l}5 \text { machines with } \\
\text { capacity of } 14.000 \mathrm{~m} 3\end{array}$ & - & - & - & - \\
\hline $\begin{array}{l}\text { Night lighting } \\
\text { system }\end{array}$ & Exists & Exists & Exists & - & - \\
\hline Ski jump & 2 with; $70 m-90 m$ & - & $\begin{array}{l}3 \text { with; } \\
90 \mathrm{~m}-35 \mathrm{~m}- \\
15 \mathrm{~m}\end{array}$ & - & - \\
\hline $\begin{array}{l}\text { Cross country } \\
\text { tracks }\end{array}$ & $35 \mathrm{~km}$ & $5 \mathrm{~km}$ & $15 \mathrm{~km}$ & - & - \\
\hline $\begin{array}{l}\text { Destination } \\
\text { from Sarajevo }\end{array}$ & $25 \mathrm{~km}$ from airport & $30 \mathrm{~km}$ & $100 \mathrm{~km}$ & $80 \mathrm{~km}$ & $140 \mathrm{~km}$ \\
\hline $\begin{array}{l}\text { Local } \\
\text { population }\end{array}$ & 425.000 & 30.000 & 70.000 & 17.000 & 4.000 \\
\hline
\end{tabular}

$\mathrm{BH}$ was the symbol of winter tourism in former Yugoslavia. 1984 Winter Olympics secured many mountains international acclaim. XIV Winter Olympics (1984) were considered as one of the most successful of its time. Today, Olympic resorts host a new generation of skiers and snowlovers, hitting the slopes with Olympic quality skiing without the outlandish prices and long waiting ques. However, these resorts are one of the last undiscovered regions with vast tracks and untouched nature of the Southern Alps. As such they represent an ideal tourism destination for hikers and walkers, as well as for adventurers and nature lovers (Bhtourism, 2010).

The beauty of the Bjelasnica Mountain is augmented by the temper of its climate. Bjelasnica's highest part, 300 meters in length, towards the Adriatic Sea, represents a border of impact of 
two climates - Mediterranean and Continental that results in rain and snow precipitation in autumn and great amounts of snow in the winter which retains until late in the spring. The highest temperature is $24^{\circ} \mathrm{C}$ and the lowest is $-41^{\circ} \mathrm{C}$. Thick green grass covers the mountain in the summer while winters attract 4 meters.

The greater area of Bjelasnica and Igman, including neighboring Visocica and Treskavica mountains (around 100,000 ha), has a long list of attractions such as mountain scenery with expansive vistas, river-cut limestone canyons, caves, rich forest, diverse flora, endemic and medicinal herbs and endangered fauna. However, the greatest and most sustainable growth opportunities lie in attracting new visitors, who will seek out Bosnia's inherent appeals. These are primarily niche market segments, such as: "soft outdoor adventurists", hikers, fishermen, river rafters, birders (migratory season only) and history/culture enthusiasts. Most of this growth will come from the more traditional tourism-producing markets in Europe, as well as neighboring regional markets.

Bjelasnica is an ideal place for winter holidays especially in the period from November to May, with snow drifts of a couple of meters in height which are a particular challenge for winter sports lovers. Winter season is particularly interesting because of the landscape of the mountain under snow, which is somewhat like a white desert covered with rays of sunshine, above which there is nothing but the areal landscape.

During the Olympics at Bjelasnica and Igman, the competitions in Alpine Skiing (Downhill, Giant Slalom and Slalom), Nordic skiing (Cross-country skiing, Nordic combined), Biathlon and Ski Jumps took place. Beside traditional disciplines, Bjelasnica is also trying to put up with the latest trends with night skiing. Ski run on 8345 meters is perfect for skiers and snowboarders of various skill levels, those looking for adventure or those with young children. Due to an increased market demand and interest in Bjelasnica and Igman resorts, the local authorities and a number of private companies have made considerable investments in the infrastructure and particularly in accommodation capacities in the last five years. This resulted in a huge increase in a number of beds (hotel with 240 beds) available at the mountain, and particularly in an increased number of condominiums (2,000 beds).

Bosnia and Herzegovina developed an authentic gastronomy familiar to many, with which it enriches its tourism and represents its culture, tradition and mode of life Bosnian cuisine is influenced by Eastern and Western. Bosnian dish is tightly connected to Greek, Turkish, and other Mediterranean cuisines. Gastronomy on Bjelasnica is one of the main reasons that can assure an increase in the service quality. The richness of natural tastes, that became a brand for $B \& H$ (such are burek and čevapčići) can make a pleasant stay and serve as a nice added value to those who came to visit mounting in $\mathrm{BH}$. The other feature of the local cuisine is that local food producers can make supply from neighboring villages. The latest trends of organic food can be linked to the local economy, which should be able to ensure a $100 \%$ bio diet. This segment could be one of the future characteristics of future mountain tourism in $\mathrm{BH}$.

As initial trigger to be used for young and curious skiers and snowboarders, who are less attach to traditional ski centers could be attracted to Bjelasnica with the lower prices. BH and Bjelasnic 
can provide the expected level of service and tourism quality compared to the price. $\mathrm{BH}$ is relatively still not too expensive, and as such can attract tourists on budget, young people and backpackers. Bjelasnica has enormous potential for further developments; however, there is a need for overarching cooperation across different sectors that will trigger investment in infrastructure and superstructure. Having in mind that Bjelasnica ski resort has not developed long term strategy yet, nor has it fulfilled preconditions for mass tourism, they can focus on domestic clients, regional clients and for the beginning youth clients from Europe. At later stages, increased capacities in hotel accommodation and introduced preconditions for a more mass tourism, Bjelasnica has the potential to attract more tourists from Europe and the rest of the world, as well.

\section{Methodology}

A series of qualitative techniques (focus groups, personal interviews, site visits - observation) are used are used to identify the competitive positions and strengths of five ski resorts in $\mathrm{BH}$. Initially, officials from ZOI'84, legal successor of the Organization Committee of the XIV Winter Olympic Games with all its sport and leisure facilities, were conducted and personal interviews were conducted about ski-resorts in $\mathrm{BH}$ (ZOI84, 2010). Researchers from a marketing management class asked questions about past and current situation of winter tourism in $\mathrm{BH}$ in these personal interviews. Furthermore, researchers went on a site visit to Bjelasnica and Igman ski resort where they conducted a focus group with the site managers and technical personnel of the ski center. In this focus group, researchers asked structured questions about comparative positions of different ski-resorts in $\mathrm{BH}$ in terms of differential advantages and disadvantages of these resorts. Finally, researchers conducted personal interviews with the officials of one travel agency in Sarajevo. Findings received from personal interviews and the focus group study were analyzed based on Porter's generic competitive strategies.

\section{Research Findings}

\section{Cost Leadership}

Even though ski resort Vlasic holds the lowest prices, the absolute cost leader is ski resort Jahorina. It has the greatest ski lift capacity, it is available to more than 25 kilometers of trails for skiing, and a variety of trails is remarkable, from slopes for beginners to the slopes for top skiers. Jahorina has a developed a strong tourist infrastructure. It is very important for the evaluation of basic accommodation facilities on Jahorina is that they are objects of recent construction, as well as that it has a well organized and edited the accompanying commercial equipment for tourist accommodation (rental of ski equipment, service, ski schools, swimming pools, gyms, saunas, fitness etc. The advantage of this ski center is the fact that almost the entire territory of Jahorina is covered with wireless internet network.

Bjelasnica and Igman, as the market followers, are very close to Jahorina in terms of tourist offer, accomodation, and the overall experience. They offer challenging ski experience, have a convenient location, variety of skiing, etc. Even though they have less slopes than Jahorina, they 
are longer. The advantage that ski resorts Bjelasnica and Igman has, compared to all other resorts, are the machines for making snow. And, besides Vlasic are the only with ski jumps. The market follower, Vlasic, is the best established ski centre in B\&H. It is the leader in accomodation terms, and holds the second position when it comes to capacity of ski lifts. Vlasic is developing very fast, and it has a great potential of becoming market challenger. The other ski resorts are Blidinje and Kupres. They are not as developed as other resorts, but are moving towards the successfull business. They have already established decent offers for tourists, like entertainment, leisure, wellness, ect.

\section{Differentiation}

Each of these ski resorts has a something which differentiates them from others. Jahorina has several hotels which are ideal for conferences and meetings, it has the highest lifts, skiing capacity up to $10.000 \mathrm{per} / \mathrm{h}$, infrastructure is in good condition since not affected by the war, one of the most popular winter resorts in the region. When it comes to Bjelasnica and Igman, they offer a great ski jumping venue ever since 1984 Olympic, there is thick forest that allows the longest skiing season in the region (200 days), it the steepest slopes in the region, horsedrawn carriage rides through the snow, etc. What makes Vlasic unique are European standard hotels, close distance to other markets - Croatia and Slovenia, the hottest venue for celebration of new year, preservation of the very old tradition of sheep breeding (Vlasic or Travnik cheese).

Blidinje has a nature lake that helps a year-round tourism, it is one of the highest peaks in the country $(2.227 \mathrm{~m})$, it is rich with variety of Mediterranean plant and animal species. Kupres is provided with 300 days sun shine that makes it the all year-round tourism resort, and it is close distance to other markets - Croatia, which attracts more tourists from that country.

\section{Focus Strategy}

What all ski resorts should do is to choose some segment to focus on, segment which will make them especially attractive. So far, $\mathrm{BH}$ resorts have similar focal points. They are focusing on developing better ski slopes, hotel and service offers, as well as extra activities that will attract more tourists.

Jahorina should focus on widening resort spaces in order to meet the needs for any future potential expansion.

Since Bjelasnica and Igman have administrative problems due to multiple authorities responsible for the resort, should put their focus on that, or on building new facilities and health centers. When it comes to Vlasic and Blidinje, their focus should be on developing more indoor and outdoor activities. Kupres has a limited accommodation and ski lifts capacity, so they should focus on developing in that area.

Winter tourism at Jahorina resort occupies the position of market leader, due to its highest lift skiing capacity and best quality in accommodation, health service center, and many other 
infrastructure and facilities that are not affected by the past war. The only disadvantage perceived to be challenging this resort is the limitation in the available space to meet the needs for any future potential expansion. Igman and Bjelasnica resort is occupying the challenger position with huge space that might be needed for any possible expansion in the future. This resort has the potential to occupy the position of market leader in the future as it has a great ski jumping venue ever since 1984 Olympics, a thick forest that allowing 200 skiing days, the steepest slopes in the region, the longest cross country tracks, and one of the highest peaks in the region. The very poor infrastructure and administrative difficulties of the resort being under the authority of the Sarajevo Canton and three municipalities (Hadzici, Trnovo and Ilidza) are the main disadvantages and challenges that facing this resort to become a market leader.

While Vlasic resort is recently occupying the third position in the market, as a market follower, it has a huge capacity and lots of features that could bring it to market challenger. This resort is the hottest venue for celebration of New year and is popular since 1991 international ski jumping competition. The resort preserves the very old tradition of sheep breeding (Vlasic or Travnik cheese) and it houses hotels that maintain European standards. The resort is very close to the major markets of Croatia and Slovenia. The main disadvantage of this resort is its distance to the regional international airports, particularly from the Capital "Sarajevo" (100 $\mathrm{km}$.). Vlasic doesn't have the unique image that was created for both Jahorina and Bjelasnica \& Igman resorts due to hosting the Olympic Games, which prevent it to compete on the position of market leader in the future unless similar opportunities offered to it too.

Research results show that Blidinje resort occupies the position of the market fast mover because it has certain features that could improve its position in the future. The resort has a natural lake that helps a year-round tourism, rich variety of plant and animal life from Mediterranean climate and has one of the highest peaks in $\mathrm{BH}(2.227 \mathrm{M})$. Finally, Kupres resort occupies the position of market nicher with its shortest skiing days, as it has $\mathbf{3 0 0}$ days sun shine that makes it the all year-round tourism resort more than a winter tourism resort. It is attracting people from Croatia than anywhere else in the region.

\section{Conclusion}

When it comes to determining competitive strategy of a certain industry, Porter's model offers the best understanding and explanation. This model contains the appropriate strategies firms should follow when they are entering certain business. These generic strategies are suggesting different requirements which are important for success, which is further indication of difference in structure and the culture of a company. When it comes to culture, it is very important aspect of competitive success. It can significantly boost the competitive advantage for the strategy, if it is appropriate. Generic strategies in Porter's model indicate that not all the strategies are appropriate for every industry. The focus of every strategy is competitive advantage, which requires firms to make a selection. If a firm is going to gain advantage, it should choose the competitive advantage it wants and domain within which it will attain that advantage. 
BH Mountains, particularly the ski resorts of Bjelasnica \& Igman and Jahorina which hosted Winter Olympic Games in 1984, have long known for their winter tourism opportunities. BH has a great potential for winter tourism due to a number of reasons including the natural beauty of its mountain range, proximity of major mountains to city centers and major airports, proximity to western European markets. Each ski resort in $\mathrm{BH}$ possesses unique characteristics that can be used to differentiate its offerings in marketing. Research results indicate that Jahorina can be promoted as a family vacation winter destination with its high accommodation potential and suitable skiing infrastructure for youngsters and non-professionals. The main positioning theme for this resort can be entertainment and fun for families. On the other hand, Bjelasnica and Igman can be positioned as the resort for skiing professionals and learners considering its technical infrastructure that was used in winter Olympics. Also, close proximity of this resort makes the reach easy for ski-enthusiasts living in Sarajevo and nearby destinations. Vlasic resort has similar benefits with Jahorina as it has great accommodation potential and entertainment opportunities. Vlasic can also be presented as a family vacation and entertainment destination but it can target different markets compared to Jahorina such as Croatia, Slovenia and other European markets. Finally, Blidinje and Kupres can act as nich products in skiing and go after focused target markets. These resorts may consider developing a vacation theme that combines skiing and mountain sports which may attract specific target markets from various age groups. The common disadvantage between the five winter resorts is that only a fraction of their huge potential and opportunities for winter sports is being used due to insufficient infrastructure and facilities at the mountains including lack of vertical transportation, ungroomed ski slopes and too few overnight accommodations. These mountains and resorts have great opportunities for further development that require strong and experienced strategic partners that are able to provide the investment capital and introduce new managerial skills and marketing plans. If managed properly, winter tourism can impact $\mathrm{BH}^{\prime}$ s gross national income to a great extend by enjoying the benefits of invisible exports such as tourism receipts and revenues. In the due course, winter tourism can provide employment, generate income, liven up and preserve hundreds of beautiful villages with old traditional life-styles in the heart of Europe that are at the risk of extinction.

To develop winter tourism in $\mathrm{BH}$ further in the future, a comprehensive strategy should be developed covering all necessary aspects with participation from all the stake holders. The implementation should be thorough and without exceptions. For more effective marketing and management strategies, collaboration and cooperation of all parties at stake is necessary. This is especially true for Bjelasnica and Igman resort which has suffered most from recent Bosnian war. Future strategies should give priority to the restoration of basic infrastructure and superstructure needed for tourism. Providing high quality services for European tourists should also be a priority to attract tourists from nearby European markets. Tourism is a beautiful mosaic and requires full cooperation and contribution from all to be successful.

\section{References}

Bhtourism (2010). Retrieved on $15 \quad$ May 2010 from $<$ www.bhtourism.ba/eng/yournextadventure.wbsp >. 
Dibb, S, and Simkin, L (2009). Marketing Essentials. London, UK: Cengage.

Enjoybosnia (2010). Retrieved on 15 May 2010 from <www.enjoybosnia.com/page-alPlanine.html>.

FIPA (2010). Winter Tourism Investment Opportunities in Bosnia and Herzegovina. Retrieved on 10 March 2010 from <http://www.br-agency.org/UserFiles/File/SKI_CENTERS.pdf>.

Hitt, M.A., Black, J.S., Porter, L.W. (2009) Management, $2^{\text {nd }}$ edition. Pearson Education, Inc., Upper Side River, New Jersey 07458

Kotler, P. and Keller, K. L. (2008). Marketing Management. Int. Ed. Upper Saddle River, New Jersey, USA: Pearson.

Mooradian, T.A., Matzler, K., Ring. L.J. (2012) Strategic Management, Pearson Education, Ink Porter, M.E. (1985) Competitive Advantage, Creating and Sustaining Superior Performance.

Porter, M.E. (1998) The Competitive Advantage of Nations. Palgrave Macmillan, 175 Fifth Avenue, New York, NY 10010

Bachelor of International Management (n.d.) Porter's Three Generic Strategies. Retrieved on 24 August 2013 from <http://www.youtube.com/radio_redirect?list=RD38kNPqxwdFQEo>

ZOI84 (2010). Retrieved on $15 \quad$ May 2010 from <http://www.zoi84.ba/index.php?lang=en\&sel=1>. 